\title{
El texto narrativo para fortalecer la competencia comunicativa del ELE
}

\author{
Andrea Lorena Aponte-Buitrago*
}

* Magíster(c) en Lingüística. Docente catedrática de la Escuela de Idiomas, Universidad Pedagógica y Tecnológica de Colombia, Tunja, Colombia.

Correo electrónico:

andrea.aponte@uptc.edu.co

Recibido: 11 de marzo del 2014 Aprobado: 26 de mayo del 2014

Cómo citar este artículo: Aponte-Buitrago, Andrea Lorena "El texto narrativo para fortalecer la competencia comunicativa del ELE". Rastros Rostros 16.30 (2014): 47-55. Impreso. doi: http://dx.doi.org/10.16925/ ra.v16i30.817

\begin{abstract}
Resumen
Este artículo presenta diversos aspectos de una investigación sobre la enseñanza de español como lengua extranjera (ELE). El objetivo es fortalecer la competencia comunicativa de los extranjeros estudiantes del ELE, por medio de diferentes textos narrativos: la fábula, el cuento, el mito y la leyenda. El propósito de este proyecto fue revisar, aplicar y diseñar una cartilla, que tuvo diversos textos narrativos con ejercicios y actividades. En relación con la metodología, este estudio fue experimental. El método fue inductivo en la medida en que tanto para la aplicación como para el análisis de resultados, se contó con la participación de un número limitado de los extranjeros que visitan la Universidad Pedagógica y Tecnológica de Colombia (UPTC) o la ciudad de Tunja. Como conclusión se detectó que los textos narrativos (fábula, cuento, mito y leyenda) sirvieron como estrategia para el mejoramiento del ELE. Del mismo modo, los textos fueron adecuados, y las actividades y los ejercicios fueron dinámicos para los extranjeros.
\end{abstract}

Palabras clave: competencia comunicativa, cuento, ELE (español como lengua extranjera), fábula, leyenda, mito.

\section{The Narrative Text as a Way to Strengthen the Communicative Competence of SFL}

\begin{abstract}
This article presents various aspects of a research study into the teaching of Spanish as a Foreign Language (SFL), the objective of which was to strengthen the communicative competence of foreign SFL students through the use of different narrative texts: fables, tales, myths and legends. The project aimed to revise, apply and design a reading workbook with various narrative texts, along with exercises and activities. In terms of the methodology applied, this was an experimental study, and used an inductive method insofar as it involved the participation of a limited number of foreign students visiting Universidad Pedagógica y Tecnológica de Colombia (UPTC) or the city of Tunja for both the application and analysis of results. It was found that the strategy of using narrative texts (fables, tales, myths and legends) helped improve SFL. Likewise, the foreign students found the texts to be appropriate, and the activities and exercises to be dynamic.
\end{abstract}

Keywords: communicative competence, tale, SFL (Spanish as a Foreign Language), fable, legend, myth.

\section{O texto narrativo para fortalecer a competência comunicativa de ELE}

\section{Resumo}

Este artigo apresenta diversos aspectos de uma pesquisa sobre o ensino de ELE (espanhol como língua estrangeira). O objetivo é fortalecer a competência comunicativa dos estrangeiros aprendizes de ELE, por meio de diferentes textos narrativos: a fábula, o conto, o mito e a lenda. O propósito deste projeto foi revisar, aplicar e elaborar uma cartilha que tivesse diversos textos narrativos com exercícios e atividades. Com relação à metodologia, este estudo foi experimental. O método foi indutivo na medida em que tanto para a aplicação quanto para a análise de resultados, contou com a participação de um número limitado dos estrangeiros que visitam a Universidad Pedagógica y Tecnológica de Colombia (UPTC) ou a cidade de Tunja. Como conclusão, detectou-se que os textos narrativos (fábula, conto, mito e lenda) serviram como estratégia para o melhoramento do ELE. Do mesmo modo, os textos foram adequados, e as atividades e os exercícios foram dinâmicos para os estrangeiros.

Palavras-chave: competência comunicativa, conto, ELE (espanhol como língua estrangeira), fábula, lenda, mito. 


\section{Introducción $^{1}$}

En la actualidad es evidente que los estudiantes extranjeros presentan falencias de lectura y escritura, y eso afecta su competencia comunicativa. Por lo tanto, en esta investigación vale la pena tener en cuenta que el estudiante de ELE necesita estar incentivado durante el proceso de lectura, aprehensión y comprensión de diversos textos, para que pueda desarrollar sus habilidades de comprensión lectora en forma adecuada y exitosa y lograr ser competente comunicativamente. Hoy en día, no existe suficiente material dirigido a los estudiantes de ELE a nivel avanzado. Por lo tanto, vale la pena presentar una cartilla que tenga como propósito contribuir significativamente en el mejoramiento de las habilidades comunicativas en ELE; esa cartilla se basa, fundamentalmente, en textos narrativos, tales como la fábula, el cuento, el mito y la leyenda.

Desde esta perspectiva, el propósito de este proyecto fue diseñar y aplicar una cartilla que contara con diversos textos narrativos, ejercicios y actividades que contribuyeran a fortalecer y mejorar la competencia comunicativa de los extranjeros estudiantes de ELE. Esta investigación se fundamentó en algunos niveles del Marco común europeo de referencia para las lenguas (MCERL; García 26). De esta manera, este proyecto tuvo en cuenta que los estudiantes de ELE estuvieran en un nivel intermedio (B2) y avanzado ( 1 1 y C2) de español. Finalmente, las actividades y los ejercicios de la cartilla se enfocaron más en lo pragmático que en los aspectos gramaticales, ya que se supone que los estudiantes, estudiantes de ELE, reconocen el uso de la lengua en actos reales de comunicación y se apropian de expresiones que hacen parte de la realidad comunicativa de los colombianos y en especial de Boyacá.

\section{Antecedentes}

Para cumplir con el objetivo principal de este proyecto, se consideró necesario buscar información acerca de otros trabajos que tuvieran relación con el tema de investigación; esto fue de gran ayuda, debido a que esas investigaciones dieron a conocer talleres y actividades lúdicas para la enseñanza del ELE. Estas sirvieron de soporte a lo largo de este proceso investigativo.

Este artículo de investigación científica es producto del proyecto de una joven investigadora de la Universidad Pedagógica y Tecnológica de Colombia, desarrollado en el 2013, y pertenece al grupo de investigación ELEX de la Escuela de Idiomas de la UPTC.
A continuación, se presentará la síntesis de los trabajos, cuyas conclusiones y recomendaciones ayudaron a que en esta investigación se tuvieran en cuenta y se utilizaran de una mejor forma.

\section{Una aproximación a la enseñanza del ELE}

Esta investigación fue realizada por Nory Cecilia Pazos (1-75). El objetivo general fue describir y aplicar pasos de una metodología, en un hablante de lengua inglesa, en el aprendizaje del ELE. El proyecto se enmarcó en un estudio de caso de corte cualitativo. El estudiante analizado fue Jonathan Bernard Jakubas. Él es de Minneapolis, Estados Unidos. Esta investigación fue el resultado de una experiencia de inmersión en los Estados Unidos, en la que a través de la interacción y la motivación el extranjero pudo lograr el aprendizaje de una lengua extranjera. Como conclusiones de la investigación, se detectó que el uso del lenguaje oral y diario lo motivó a practicar el nuevo idioma de una forma más real, natural y significativa.

La investigadora se basó en los pasos metodológicos de Krashen y Terrel: etapa de pre-producción (motivación, interacción y estado afectivo); etapa de producción temprana (traducción y repetición); etapa de habla espontánea (aculturación y extrapolación en recursos lingüísticos), y etapa de fluidez intermedia (apropiación de contextos culturales). Todos los pasos anteriores le permitieron aprender ELE. Finalmente, el lenguaje oral, la motivación y la interacción fueron ejes fundamentales para el aprendizaje de una lengua extranjera.

\section{Material educativo computarizado (MEC) para la enseñanza del ELE}

Este proyecto de investigación fue desarrollado por Marleny Montañez y Carolina Suárez (1-56). El objetivo general fue elaborar un material educativo computarizado (MEC) para la enseñanza-aprendizaje del ELE en el nivel A1 (MCE) y explicar su estructura, funcionamiento y uso. La investigación fue de tipo descriptivo. La población a la que se dirigió este proyecto fueron los docentes, los estudiantes de la Escuela de Idiomas de la UPTC y los estudiantes extranjeros que se interesan por el aprendizaje del ELE. La metodología empleada por las investigadoras se basó en las siguientes etapas: la recolección de la información por medio de una entrevista, el análisis de los datos y las conclusiones, para finalmente diseñar el material educativo computarizado 
para la enseñanza del ele. Como conclusiones de la investigación, con base en los lineamientos del MCERL, se pudieron seleccionar los contenidos para el material educativo computarizado. Asimismo, tuvieron en cuenta el enfoque comunicativo para el diseño de las actividades del material educativo. Finalmente, las investigadoras aludieron a diversas recomendaciones sobre su proyecto, encaminadas a la creación de diversos materiales para la enseñanza del ELE.

\section{Marco teórico}

En relación con la fundamentación teórica, se ha considerado oportuno reconocer los aportes de algunos autores que tratan los temas de aprendizaje, enseñanza y las estrategias para el mejoramiento del ELE, la competencia comunicativa en una lengua extranjera, el texto narrativo, la fábula, el cuento, el mito y la leyenda.

\section{Aprendizaje, enseñanza y estrategias para el mejoramiento de ELE}

Como es de conocimiento común, el español se ha convertido en un idioma universal, como lo son el inglés y el mandarín. De esta forma, parafraseando a Espejo, Flórez y Zambrano (67), el español es una de las lenguas más habladas del mundo y ocupa el tercer lugar entre los idiomas con mayor número de hablantes. Por lo tanto, los extranjeros llegan a los países hispanohablantes para lograr hablar este idioma con propósitos académicos y económicos, entre otros, ya que el español, además de ser una lengua de negocios, es una lengua de cultura.

La enseñanza del ELE se debe concebir como un todo, en el que los estudiantes adquieren conocimientos y los aplican en los diferentes contextos académicos y sociales como el aula de clase, la casa, el parque, la calle, entre otros; en estos lugares están inmersos con el español y pueden aprender vocabulario y expresiones nuevas provenientes de los hablantes colombianos. De esta forma, Vine y Ferreira afirman que: "la adquisición de segundas lenguas (ASL) requiere la atención de dos enfoques o paradigmas, el primero se fundamenta en las teorías cognitivas de la psicología y de la lingüística, y el segundo paradigma se enfoca en la teoría sociocultural" (145).

Asimismo, de acuerdo con Flores (171-172), el dominio de una lengua extranjera le permite al estudiante de ELE ampliar e interactuar en su horizonte cultural. De esta forma, en esta investigación se tuvieron en cuenta algunos niveles del MCERL (García 26). En este sentido, los extranjeros de nivel intermedio y avanzado ya han aprendido, practicado y mejorado en lo relacionado con la gramática, la fonética, el léxico o el vocabulario y en el fortalecimiento de las cuatro habilidades: hablar, leer, escribir y escuchar. De esta manera, los ejercicios y las actividades buscaban el fortalecimiento de la competencia comunicativa de los estudiantes del ELE. En esta, ellos tuvieron la oportunidad de aprender, comprender y practicar el vocabulario y las expresiones provenientes de las fábulas, los cuentos, los mitos y las leyendas de Boyacá y Colombia.

\section{La competencia comunicativa en una lengua extranjera}

La competencia comunicativa es la capacidad a la que se dirige la atención con proyectos que tengan como eje el ELE. Un extranjero, además de poder actuar lingüísticamente en contextos académicos, necesita transmitir sensaciones, emociones y sentimientos de la misma manera que con su lengua materna. Asimismo, esta competencia es tan importante como vital dentro del contexto de enseñanza y aprendizaje del ELE, puesto que, a través de esta, se pueden trasmitir pensamientos, emociones y sentimientos que sobre un asunto o tema un estudiante quiere expresar. Además, brinda la posibilidad de que los estudiantes sean cada vez más críticos y reflexivos. De esta manera, los docentes y estudiantes deben generar un clima de aceptación, interés, ayuda, creatividad y dinamismo, y esto da lugar a que en el fortalecimiento de la competencia comunicativa se haga un apropiado uso del lenguaje, el manejo de reglas ortográficas y la promoción de la imaginación, entre otras. De esta forma, se buscó concatenar estas habilidades lingüísticas con el contexto sociocultural colombiano.

Parafraseando a Cardozo (1-2), la competencia comunicativa busca fortalecer uno de los aspectos inherentes a las relaciones sociales: el uso correcto y apropiado de la lengua. Además, la potenciación de la competencia comunicativa conlleva el desarrollo de algunas competencias ciudadanas tales como saber escuchar a los demás y valorar los puntos de vista diferentes del propio. Esta "metacompetencia" se fundamenta en la interrelación de la competencias interpretativa, propositiva y argumentativa. 


\section{El texto narrativo}

Aristóteles y Platón fueron los primeros en aportar sus ideas en torno al texto narrativo; es así como en palabras de Aristóteles, citado por Garrido, "la fiebre narratológica se orienta hacia el estudio de (los mitos, fábulas, leyendas, lo maravilloso, en suma) que el paradigma interpretativo corresponde siempre al hombre y se lleva a cabo a la luz del proyecto humano" (12). Asimismo, Brewer, citado por Muth, define la narración como:

[un] discurso que trata de incorporar lingüísticamente una serie de acontecimientos ocurridos en el tiempo ... [y que tienen] una coherencia causal o temática'. Da el siguiente ejemplo de texto narrativo: 'El nene vio una flor. Cortó la flor. Le dio la flor a su mamá. La descripción 'es un discurso que apunta a incorporar lingüísticamente una escena perceptual estacionaria'. La exposición 'es un discurso que apunta a representar lingüísticamente los procesos lógicos abstractos implícitos ... [tales como] la inducción, clasificación y comparación. (18)

Por lo tanto, los textos narrativos deben tener un ingrediente que logre captar la atención del lector, en este caso, al extranjero estudiante de ELE. Asimismo, la categoría narrativa incluye textos tales como mitos, leyendas, cuentos, fábulas, en suma todo lo maravilloso.

La teoría narrativa abarca los siguientes requisitos, de acuerdo con Garrido:

brevedad (ateniéndose a lo esencial para la causa y eliminando lo accesorio), credibilidad (debe justificarse no sólo lo verosímil sino incluso lo increíble), carácter ético (ha de reflejar una postura moral) y carácter patético (es importante que las acciones revelen una notable intensidad de las pasiones con vistas a despertar la emotividad del auditorio). (12)

\section{La fábula}

El primer tipo de texto narrativo escogido fue la fábula. Este se define como un relato breve e imaginario, es antiquísima y viene de la poesía griega con Aristóteles. Los personajes típicos dentro de esta clase de textos pueden ser animales u objetos animados. Las principales características son las siguientes: en primer lugar, sus personajes típicos son, casi siempre, animales; utiliza la personificación: esta figura hace referencia a la atribución de cualidades y defectos humanos a animales u objetos. A su vez, la fábula busca dejar al lector una enseñanza o moraleja. Los escritores de fábulas se llaman fabulistas. Los más reconocidos son:

- Rafael Pombo: colombiano que nació en 1833 y murió en 1912. Era un hombre de una cultura amplia y universal. Fue poeta romántico, escritor del amor y la naturaleza, pensador, político, militar, traductor y fabulista. Escribió poemas, novelas y fábulas. Las más conocidas son "Cutufato y su gato", "La paloma y el niño", "La gallina de los huevos de oro", entre otras.

- Félix María Samaniego: español nacido en 1745 y fallecido en 1801. Samaniego es considerado el mejor de los fabulistas españoles. Las fábulas de Samaniego se inspiran en las obras de los fabulistas clásicos Esopo y Fedro y también de las del francés La Fontaine; muchas de sus fábulas se destacan por su espontaneidad y gracia. Algunas de sus fábulas son "La lechera", "Las ranas que pedían rey", "El parto de los montes", "La cigarra y la hormiga", "La codorniz", "Las moscas", entre otras.

- Esopo: griego que vivió en el siglo vi a. C. Pocos datos existen sobre la vida de Esopo. Relató fábulas en las que personificaba animales que fueron transmitidas de forma oral. Las fábulas que conocemos hoy en día son versiones que se han reconstruido a partir de la reescritura del fabulista griego. Él ha inspirado e influido a fabulistas como Jean de La Fontaine en Francia, en el siglo XVII, y Félix María de Samaniego, en España, en el siglo XviII. Algunas de sus fábulas son "El águila y los gallos", "El águila y la flecha", entre otras.

- Jean de La Fontaine: autor francés nacido en 1621 y fallecido en 1695. La Fontaine fue un gran cuentista de fábulas. Estas fueron publicadas en múltiples ediciones ilustradas. Algunas fábulas son "El gato viejo y el ratoncito", "El gato y la zorra”, entre otras.

\section{El cuento}

El segundo tipo de texto narrativo seleccionado fue el cuento. Se define como una narración de hechos reales o ficticios en la que sus personajes se ubican en un lugar y tiempo determinado. De acuerdo con Muth:

El cuento es una forma particular de narración cuyo contenido suele ser diferente del contenido de otro tipo de discursos. Tiene una estructura o estructuras diferentes de la descripción y la exposición. Tiene tramas, personajes que interactúan socialmente, y temas; pueden 
tener una visión interna, variar el punto de vista y contener prefiguraciones. Contiene un problema o conflicto o ambos a la vez, gira en torno a los propósitos de los personajes y tiene un tipo de acción y de resolución, con diversos elementos que se relacionan con encadenamientos temporales o causales. El cuento es a menudo caracterizado por rasgos lingüísticos tales como 'Había una vez', tiene una fuerza de entretenimiento, o estéticoliteraria, y por lo general evoca sensaciones afectivas tales como el interés, la sorpresa y el suspenso. (21)

El cuento tiene una estructura de tres partes. Primero, está el inicio o introducción: es la parte en la que se da a conocer algún personaje y en la que se presenta un asunto y un conflicto. Luego, se encuentra el nudo o trama. Es la parte central de la narración: amplía el asunto y el conflicto, a través de una serie de hechos y aventuras que se van enlazando y complicando. Por último, está el desenlace, que es el final de la historia, el momento en el que se da una solución al asunto y al conflicto. Adicionalmente, el cuento puede terminar en un final feliz o triste. Los cuentos se clasifican en las siguientes clases:

- Cuento fantástico: relatos en los que se narran acciones cotidianas o comunes pero que en cualquier momento aparece un hecho sorprendente o irreal. En esta clase de cuento aparecen personajes reales e irreales, como seres invisibles o espirituales, hadas o duendes. También puede ser una narración cuyos protagonistas sean animales, como en el caso de las fábulas. Se centra en la realidad, la imaginación, en la fantasía y en la sorpresa.

- Cuento de hadas y duendes o maravilloso: son historias en las que aparecen personajes mágicos y sobrenaturales, que intervienen en los asuntos de los seres humanos. Sus personajes pueden ser duendes, genios, brujas, diablos, ogros, princesas, príncipes, etc.

- Cuento realista: es una observación directa de la vida en diversos aspectos: psicológico, religioso, humorístico, satírico, social, filosófico, histórico, costumbrista o regionalista. Algunos escritores destacados son Palacio Valdés, Unamuno, Quiroga, entre otros.

- Cuento de ciencia ficción: se cuentan historias acerca de sucesos futuros en planetas o lugares diferentes a la tierra. Además, los escritores de este género pueden escribir sobre temas relacionados con avances científicos.

- Cuento de terror: la temática se caracteriza por la presencia de fantasmas, apariciones, objetos ina- nimados que se mueven o hacen ruidos extraños. Estos elementos contribuyen a que el lector experimente sensaciones de sobresalto, angustia y terror. En los cuentos de terror aparecen sombras, seres fantasmales, cadáveres en castillos, en mansiones arruinadas o lugares sórdidos.

- Minicuento: son narraciones breves que pueden constar de una línea de hasta 200 o 400 palabras. Permiten que el lector pueda imaginar la continuación, el contexto o antecedentes del cuento.

\section{El mito}

La tercera clase de texto narrativo escogido fue el mito. De esta, hacen parte las narraciones transmitidas de generación en generación. Dan una explicación al origen del universo; tienen un valor ritual y sagrado e involucran dioses, semidioses y hombres en aventuras extraordinarias a través de las cuales se pretenden explicar fenómenos naturales. Los mitos se clasifican en:

- Mito cosmogónico: alude al origen del mundo. En él se menciona la nada, el caos original, el vacío y la presencia de un fundador o creador del mundo. Explica el origen de los astros, el día y la noche.

- Mito antropogénico: hace alusión al origen de la humanidad y señala la posición del hombre frente al mundo, sus deberes y su función en el seno de la creación.

- Mito teogónico: explica que, después de que el hombre creó el universo, sus primeros pobladores fueron los mismos dioses. Los dioses representan aspectos del mundo: luz, agua, montañas. Otros representan conceptos morales abstractos, como la fecundidad, el amor, la castidad.

- Mito de las grandes peregrinaciones: narra la historia de los pueblos que, en algún momento de su vida, han tenido que desplazarse en busca de mejores condiciones de vida. Estos viajes se dan generalmente obedeciendo órdenes de los dioses, quienes deciden cuándo partir y dónde detenerse para fundar un nuevo pueblo.

\section{La leyenda}

El último género de texto narrativo seleccionado fue la leyenda. Son obras literarias que fueron creadas por los pueblos para explicar sus creencias, costumbres y hechos de su historia. Sus personajes son seres humanos 
con virtudes o comportamientos muy especiales. Las leyendas se caracterizan por tener cuatro rasgos:

- Tradicionalidad: nacen como relatos orales que se transmiten de viva voz a lo largo del tiempo, entre las gentes de una comunidad o de un pueblo.

- La pretensión de veracidad: se presenta como un relato verídico, y así es considerada por la gente.

- El valor explicativo: en algunos casos, las leyendas nacen como respuesta a alguna de las cuestiones fundamentales que se plantea cualquier persona, por ejemplo, el origen de una cueva, de un precipicio o la razón de algún suceso en particular.

- El componente maravilloso: suelen incorporar numerosos elementos fantásticos, como la intervención de seres sobrenaturales o dotados de facultades excepcionales, objetos revestidos de poderes mágicos, acciones extraordinarias.

\section{Metodología}

En relación con la metodología, cabe aclarar que de acuerdo con los objetivos planteados, este estudio fue experimental, debido a que se han aplicado ocho talleres a los extranjeros estudiantes del ELE. Los talleres fueron modificados de acuerdo con el análisis de la información, y posteriormente se diseñó la cartilla final. De esta manera, de acuerdo con Camacho de Baez:

La investigación experimental es el proceso mediante el cual se manipula una variable experimental, en condiciones de riguroso control, para descubrir de qué modo y por qué causa se produce una situación o acontecimiento particular. La experimentación consiste en modificar, bajo cuidadoso control, las condiciones de un hecho y en observar e interpretar los cambios que ocurren en este último. Para lograr los objetivos de la investigación científica que son explicar, predecir y controlar la conducta y los hechos, es necesario descubrir las relaciones de causa-efecto que se dan entre los fenómenos. Para alcanzarlo, este tipo de investigación expone un grupo llamado 'experimental' a los estímulos determinados y compara su comportamiento resultante con el otro grupo llamado de 'control' el cual no ha sido sometido al estímulo o estímulos previstos. Un ejemplo en el campo de la lingüística sería: el diálogo dirigido como alternativa de desarrollo de la lengua materna. (77)

El enfoque fue mixto, ya que incluyó tanto el cualitativo como el cuantitativo; de acuerdo con Hernández, Fernández y Baptista: "El enfoque cuantitativo: usa la recolección de datos para probar hipótesis, con base en la medición numérica y el análisis estadístico, para establecer patrones de comportamiento y probar teorías" (5); y "el enfoque cualitativo: utiliza la medición de datos sin medición numérica para descubrir o afinar preguntas de investigación en el proceso de interpretación" (8).

El método fue inductivo en la medida en que, tanto para la aplicación, como para el análisis de resultados y la publicación posterior, se contó con la participación de un número limitado de los extranjeros que visitan la Universidad Pedagógica y Tecnológica de Colombia o la ciudad de Tunja. De acuerdo con Bernal, el método inductivo:

Utiliza el razonamiento para obtener conclusiones que parten de hechos particulares aceptados como válidos, para llegar a conclusiones, cuya aplicación sea de carácter general. El método se inicia con un estudio individual de los hechos y se formulan conclusiones universales que se postulan como leyes, principios o fundamentos de una teoría. (56)

La población de la investigación corresponde a los estudiantes extranjeros que se encuentran en la ciudad de Tunja o en la UPTC. La muestra poblacional estuvo constituida por tres estudiantes de ELE.

La metodología de la investigación se fundamentó en las siguientes actividades: primero se realizaron los antecedentes y el marco teórico para tener los fundamentos necesarios durante el desarrollo de la investigación. Más adelante, se seleccionaron los textos narrativos para el diseño de los ocho talleres; se tuvieron en cuenta textos como la fábula, el cuento, el mito y la leyenda. Enseguida se hizo una primera aplicación de los ejercicios y las actividades a los estudiantes de ELE. En la primera aplicación, se hicieron cuatro talleres. Posteriormente, se analizaron los resultados provenientes de la primera aplicación de la cartilla con el objetivo de replantear los ejercicios y las actividades propuestas. Los cuatro primeros talleres incluyeron los siguientes textos narrativos: una fábula de Samaniego, "La cigarra y la hormiga"; un cuento de Tolstoi, "No era tan fácil como pensaba"; un mito colombiano, "Bochica, el maestro de los Muiscas", y una leyenda colombiana, "La mula de tres patas". Cada texto incluyó preguntas para el análisis, interpretación, proposición y argumentación.

Después, se realizó la segunda aplicación con base en los resultados provenientes de los cuatro primeros talleres aplicados. En la segunda aplicación, se realizaron 
cuatro talleres; para esta aplicación, se utilizaron los siguientes textos narrativos: una fábula de Pombo, "La pobre viejecita"; un cuento de La culpa es de la vaca, "El perrito cojo"; un mito de Tunja, "Goranchacha", y una leyenda de Tunja "El espanto del panóptico". Del mismo modo, cada texto incluyó preguntas de análisis, interpretación, proposición, argumentación y creación. Finalmente, la cartilla fue publicada con los cambios requeridos a partir del análisis de los resultados provenientes de la aplicación de los ocho talleres.

\section{Resultados}

Antes de la aplicación de los talleres, la investigadora orientó una clase de español para socializar la temática de cada uno de los textos narrativos. Los talleres aplicados se enfocaron en cuatro clases de textos narrativos: la fábula, el cuento, el mito y la leyenda. Para acompañar los textos, se usaron imágenes y, por supuesto, las actividades correspondientes para mejorar la competencia comunicativa de los estudiantes de ELE. Los extranjeros que participaron en la investigación fueron tres personas: dos alemanes y un inglés. La alemana vino a Colombia con un convenio de la Cruz Roja; el otro alemán y el inglés son profesores de su lengua materna en la ciudad de Tunja. Ellos están entre un nivel intermedio y avanzado de español.

En la clase de español, los extranjeros reforzaron sus conocimientos sobre los textos narrativos. La alemana aseveró que no sabía nada de la fábula y confundía el mito con la leyenda. Los demás extranjeros afirmaron tener un conocimiento leve de la temática estudiada. Asimismo, los tres estudiantes de ELE, por medio de la temática, conocieron y aprendieron vocabulario desconocido, expresiones nuevas, autores y, en general, la cultura de Colombia, Boyacá y Tunja.

En la aplicación de los cuatro primeros talleres, la alemana fue la única quien autorizó la toma de fotos y varios videos; los otros estudiantes no autorizaron la toma ni de fotos ni de videos.

En la primera aplicación, la alemana sintió apatía a los textos narrativos largos. Por lo tanto, los cuatro últimos talleres fueron adaptados con imágenes y textos cortos. Ella afirmó que aprendió vocabulario y expresiones desconocidas provenientes de los cuatro textos narrativos. En relación con la fábula del taller 1, las respuestas dadas por esta estudiante de ELE tendieron a ser argumentadas aunque faltó claridad y cohesión en sus análisis y reflexiones. Ella también aseguró que la historia del cuento del taller 2 fue interesante. En general, las respuestas dadas por esta estudiante de ELE en el taller 2 fueron más coherentes que en el taller anterior. En el texto del mito (taller2) y la leyenda (taller3), ella dijo que faltó una imagen para contextualizarse y comprender mejor los textos. En general, las respuestas dadas por esta estudiante de ELE fueron argumentadas, analíticas y reflexivas desde el punto de vista gramatical y permitieron reconocer un nivel de lectura socio-crítico.

El alemán, aunque fue crítico y reflexivo, le faltó profundizar más en las respuestas de la fábula (taller1). Él afirmó que la historia del cuento (taller 2) fue interesante. En general, las respuestas de este estudiante de ELE fueron coherentes, pero se percibió una debilidad a la hora de intentar argumentar sus respuestas. Asimismo, él dijo que le gustó el mito del taller 3 porque aprendió más sobre la cultura de Boyacá. Él afirmó que una de las preguntas del mito (que pedía hacer una reflexión sobre el mito leído) no fue clara; de esta manera, esa pregunta también se replanteó. En síntesis, le faltó profundizar y argumentar mejor algunas de sus respuestas del taller 3. En relación con la leyenda (taller 4), él aseguró que no encontró ninguna reflexión. Él narró una leyenda de su país. En esta narración se evidencia la interculturalidad, y se puede concluir que sí es posible lograr que la interculturalidad favorezca el mejoramiento del ELE. En general, le faltó profundizar y argumentar las respuestas dadas en la fábula y el mito; sin embargo, en el cuento y la leyenda las respuestas fueron profundas, críticas y reflexivas.

El inglés afirmó que le gustó la fábula del primer taller porque se puede aplicar en la vida real. En el cuento (taller 2), el mito (taller 3) y la leyenda (taller 4) le faltó profundizar, analizar y argumentar más en las repuestas dadas; sin embargo, él afirmó que las actividades fueron novedosas y fáciles para responder y de esta forma pudo interpretar adecuadamente las diferentes narrativas.

En síntesis, los tres extranjeros estuvieron de acuerdo en que las actividades de los cuatro primeros talleres fueron interesantes y aprendieron vocabulario y expresiones desconocidas.

Con la aplicación de los cuatro últimos talleres, se tuvieron en cuenta los resultados de los primeros cuatro talleres para replantear las actividades y los ejercicios. En los cuatro últimos talleres, los cuatro textos narrativos fueron más cortos e incluyeron imágenes; asimismo, la última actividad se fundamentó en la creación de un texto narrativo: fábula, cuento, mito o leyenda. 
De este modo, el alemán afirmó que le gustó la fábula del taller 5 porque utilizaba ironía; asimismo, él afirmó no tener creatividad para inventar una fábula porque no tiene espíritu de escritor. En relación con el cuento del taller 6, afirmó que le gustó el final de la historia, porque este dejaba una enseñanza para la vida. En la reflexión se evidencia su capacidad de interpretación y de argumentación. Además, el alemán afirmó no tener creatividad para inventar un cuento. El mito del taller 7 le llamó la atención porque entendió el por qué de la estatua en el campus de la UPTC. De esta manera, se confirma la importancia de tener en cuenta el contexto en todos los espacios en los que el aprendizaje o mejoramiento de una lengua extranjera sea prioritario. En relación con la leyenda del taller 8, el estudiante de ELE logró describir con detalles al único personaje de la leyenda. Él aseguró que no le gustó porque no le interesan las narraciones fantásticas. En general, con base en sus respuestas, es posible afirmar que es capaz de expresar sus sensaciones, sus emociones y sus gustos, y también se evidencia un nivel argumentativo considerable.

El inglés dijo que le gustó la historia de la fábula del taller 5 porque usaba el sarcasmo. Al hacer la comparación de la viejita con "María Ann Tunnette, la última reina de Francia", ratifica que el encuentro de elementos culturales de diferentes países contribuye en el mejoramiento de la competencia comunicativa en una lengua extranjera. Él afirmó que le gustó el cuento del taller 6, porque el niño tenía carácter y personalidad. El último punto lo desarrolló y creó un cuento; en este se vio reflejado su espíritu creador y propositivo. En síntesis, sus respuestas fueron críticas, reflexivas, argumentadas y creativas. En relación con el mito del taller 7, aunque la descripción que hizo de los personajes fue superficial, se reconoció un mejoramiento significativo en lo que tiene que ver con aspectos gramaticales y de redacción en general. Además, profundizó más en la reflexión que le dejó este y en la narración del mito de su país. Afirmó que le gustó la leyenda del taller 8 porque dice que a toda la gente del mundo le gustan las historias de fantasmas. En general, sus respuestas fueron críticas, reflexivas, argumentadas y creativas.

En síntesis, los dos extranjeros afirmaron que las actividades de los últimos cuatro talleres fueron más cortas y aprendieron más sobre la cultura que los rodea a diario. Asimismo, tuvieron la oportunidad de conocer expresiones y léxico nuevo que les permite comunicarse, entender y hacerse entender con los demás. Del mismo modo, el alemán y el inglés fueron más críticos, reflexivos, analíticos y creativos en sus respuestas fortaleciendo su competencia comunicativa.

\section{Conclusiones}

Por medio de esta investigación, se comprobó que los estudiantes extranjeros expresan de forma espontánea sus historias, sus vivencias particulares y las de otras personas. Del mismo modo, los estudiantes de ELE aseguraron que los ocho talleres despertaron en ellos el entusiasmo por leer y comprender diversos textos, ya que por medio de estos fue más fácil comprender y entender diferentes tipos de textos narrativos como las fábulas, los cuentos, los mitos y las leyendas. Asimismo, los extranjeros llegaron más allá de la comprensión y disfrutaron de la literatura desde el punto de vista estético y cultural.

La propuesta pedagógica, de acuerdo con los resultados de esta investigación, tendió a utilizar actividades y talleres lúdicos con los que los estudiantes estudiantes de ELE pudieron leer y comprender de forma fácil y agradable diferentes tipos de textos. Estas actividades incluyeron: uso de ocho textos narrativos e imágenes para que ellos pudieran leer, comprender y mejorar su competencia comunicativa. Finalmente, con base en los talleres desarrollados por los extranjeros que participaron en esta investigación, se puede evitar el uso de actividades monótonas para que los estudiantes no sientan apatía al leer y al comprender diversos tipos de textos.

Como conclusión, se detectó que los textos narrativos (fábula, cuento, mito y leyenda) sirvieron como estrategia para el mejoramiento del ELE, debido a que los extranjeros pudieron aprender léxico, vocabulario y expresiones nuevas provenientes de cada uno de los textos narrativos. De esta manera, se mejora la competencia comunicativa de los extranjeros estudiantes de ELE, puesto que se fortalece los aspectos que son útiles en diversas actividades comunicativas coloquiales. Además, ellos conocieron más sobre la cultura colombiana y boyacense en la que están sumergidos a diario. La mayoría de sus respuestas fueron críticas, reflexivas, argumentadas y creativas. Aunque las actividades y los ejercicios fueron dinámicos para los extranjeros estudiantes de ELE, algunas preguntas y ejercicios de los textos aplicados fueron modificados en la cartilla final con base en las observaciones que los extranjeros estudiantes de ELE hicieron acerca de los ocho talleres. Asimismo, se incluyeron imágenes para contextualizar mejor a los estudiantes de ELE. 
Las recomendaciones a las futuras investigaciones sobre ELE se enfocan en realizar diversas actividades lúdicas y entretenidas que involucren el uso de la cultura para el mejoramiento de la competencia comunicativa en ELE.

\section{Referencias}

Bernal, César Augusto. Metodología de la investigación. 2a ed. México: Pearson Educación. 2006. Impreso.

Camacho de Baez, Briceida. Metodología de la investigación cientifica. Tunja: Universidad Pedagógica y Tecnológica de Colombia, 2003. Impreso.

Cardozo, Gerardo. Programa de competencias comunicativas. Tunja: Universidad Pedagógica y Tecnológica de Colombia, 2013. Impreso.

Espejo, María Bernarda, María del Pilar Flórez e Ivonne Zambrano Gómez. "Tendencias de los estudios de ele en Bogotá". Lenguas en Contacto y Bilingüismo 5 (2013): 65-91. Web.
Flores, Guadalupe. “Técnicas y prácticas del español como lengua materna y lengua extranjera". Memorias del VI Foro de Estudios en Lenguas Internacional. México: Universidad de Quintana Roo, 2010: 171-186. Impreso.

Garrido, Antonio. El texto narrativo: teoría de la literatura y literatura comparada. Madrid: Síntesis, 1993. Impreso.

Hernández, Roberto, Carlos Fernández y María del Pilar Baptista. Metodología de la Investigación. México: McGraw-Hill, 2006. Impreso.

Montañez, Marleny, y Carolina Suárez. "Material educativo computarizado (MEC) para la enseñanza del ELE.Trabajo de grado. Universidad Pedagógica y Tecnológica de Colombia, 2009. Impreso.

Muth, K. Denise, ed. El texto narrativo: estrategias para su comprensión. Argentina: Aique, 1991. Impreso.

Pazos, Nory Cecilia. "Una aproximación a la enseñanza del ele”. Trabajo de grado. Universidad Pedagógica y Tecnológica de Colombia, 2007. Impreso.

Vine, Ana, y Anita Ferreira. "Mejoramiento de la competencia comunicativa en ELE a través de la video comunicación". Revista de Lingüística Teórica y Aplicada. (2012). Web. 